\title{
In-situ and Operando Studies with Soft X-Ray Transmission Spectromicroscopy
}

Adam P. Hitchcock, ${ }^{1}$ Chunyang Zhang, ${ }^{2}$ Haytham Eraky, ${ }^{1}$ Ladan Shahcheraghi, ${ }^{2}$ Fatma Ismail ${ }^{2}$ and Drew Higgins $^{2}$

${ }^{1}$ Dept. of Chemistry \& Chemical Biology, McMaster University, Hamilton, Canada.

${ }^{2}$ Dept of Chemical Engineering, McMaster University, Hamilton, Canada.

Soft X-ray scanning transmission microscopy (STXM) [1] is a powerful tool for nanoscale materials analysis. Ptychography [2-4], which can be measured using soft X-ray STXMs equipped with a suitable X-ray camera, provides a spatial resolution 3-10 times better than conventional STXM with the same spot size. Recently soft X-ray ptychography has been implemented in STXMs at the Canadian Light Source (CLS) and at Synchrotron Soleil. In situ and operando studies of energy conversion systems have been carried out with soft X-ray STXM [5-7] and soft X-ray ptychography [2,8-10].

Over the past decade, my group has collaborated with researchers from industry (the Automotive Fuel Cell Co-operation (AFCC) and Ballard Power) to develop and apply STXM and ptychography to characterize polymer electrolyte membrane fuel cell (PEM-FC) electrodes and materials. We have measured the distribution of the persulfonic acid ionomer in the cathodes of PEM-FC under in situ variable humidity and temperature conditions [5]. We also developed an operando system in which the electrochemical state of a material is changed with real time control of the applied potential, type of electrolyte, and the electrolyte flow rate [11]. The latter system has been used to study electrodeposition of $\mathrm{Cu}$ on $\mathrm{Au}$ from a $\mathrm{Cu}\left(\mathrm{SO}_{4}\right)$ solution, and electro-stripping of the deposited $\mathrm{Cu}$.

Recently a major improvement in the in situ flow electrochemical apparatus has been made [12]. Figure 1 presents a schematic of that improved apparatus. When compared to the device reported in 2018, the new device is much more reliable with respect to fluid leaks and electrical connections. It also features two inlet and two outlet flow channels which facilitates changing the electrolyte in minutes rather than hours and is very useful for removing air or gaseous product bubbles.

Figure 2 reports preliminary results from studies of $\mathrm{Cu}$ electrocatalysis of the $\mathrm{CO}_{2}$ reduction $\left(\mathrm{CO}_{2} \mathrm{R}\right)$ reaction, which is actively under investigation to find an economic way of turning $\mathrm{CO}_{2}$ from point sources (e.g. cement production) or direct air capture into $\mathrm{C}_{1}$ and $\mathrm{C}_{2}$ chemical feedstocks and fuels. First a mixed $\mathrm{Cu}(0), \mathrm{Cu}(1)$ catalyst layer was in situ electrodeposited from a $\mathrm{Cu}\left(\mathrm{SO}_{4}\right)_{\text {aq }}$ solution on to the thin part of the Au working electrode (Fig. 1e). After changing the electrolyte to a $0.1 \mathrm{M} \mathrm{NaHCO}_{3}$ (aq) solution, STXM stacks at the $\mathrm{Cu} 2 \mathrm{p}$ edge were measured at several potentials in order to follow the evolution of the oxidation state distribution of the $\mathrm{Cu}$ through several electrochemical cycles $(\mathrm{CV})$ in which, first the $\mathrm{Cu}$ was partially oxidized, then, at the lowest potential (-0.5 V wrt SHE) of the $\mathrm{CV}$ scan, dissolved $\mathrm{CO}_{2}$ from the saturated $\mathrm{NaHCO}_{3}$ (aq) electrolyte solution was reduced.

I will also present results from ex situ Ni L-edge studies of Ni-N-C single atom electrocatalysts being explored for $\mathrm{CO}_{2} \mathrm{R}$ [13]. We have already used STXM and product yield testing to show that excess Ni in these types of catalyst is detrimental, leading to water splitting to form $\mathrm{H}_{2}$ rather than the more desirable $\mathrm{CO}$ or $\mathrm{C}_{2}$ products. We plan to use the improved flow electrochemical apparatus for in situ studies of $\mathrm{CO}_{2}$ reduction by $\mathrm{Cu}$ nanoparticles [14], Ag-doped $\mathrm{Cu}$ [15], and Ni-N-C [16] electrocatalysts, in order to obtain mechanistic insights that may help further optimize these electrocatalysts [17]. 
References:

[1] AP Hitchcock, J. Electron Spectrosc. Rel. Phen. 200 (2015), p. 49.

[2] DA Shapiro et al, Nat. Photonics 8 (2014), p. 765.

[3] XH Zhu et al, Proc. Nat. Acad. Sci. 113 (2016), E8219.

[4] H Yuan et al, ACS Applied Nanomaterials 4 (2021), p. 621.

[5] AP Hitchcock et al, Microscopy \& Microanalysis 20 S3 (2014), p.1532.

[6] J Lim et al, Science 353 (2016), p. 566.

[7] C Gosse et al, Lab on a Chip 20 (2020), p. 3213.

[8] YS Yu et al, Nano Letters 15 (2015), p. 4282.

[9] B Bozzini et al, J. Electron. Spectrosc. Rel. Phen. 220 (2017), p. 147.

[10] DA Shapiro et al, Science Advances. 6 (2020), eabc4904.

[11] V Prabu et al, Rev. Sci. Inst. 89 (2018), p. 063702.

[12] P Ingino et al, Rev. Sci. Instr., in preparation.

[13] CY Zhang et al, ACS Catalysis, in preparation.

[14] RM Arán-Ais et al, Nature Energy 5 (2020), p. 317; Nature Comm. 11 (2020), p. 3489.

[15] TTH Hoang et al, J. Am. Chem. Soc. 140 (2018), p. 5791.

[16] MM Millet et al, Angewandte Chemie Int. Ed. 59 (2020), p. 21613

[17] STXM and ptychography was performed at the CLS, which is supported by the Canada Foundation for Innovation. We thank Dr. Martin Obst and Pablo Ingino for sharing their improved flow electrochemical cell design.

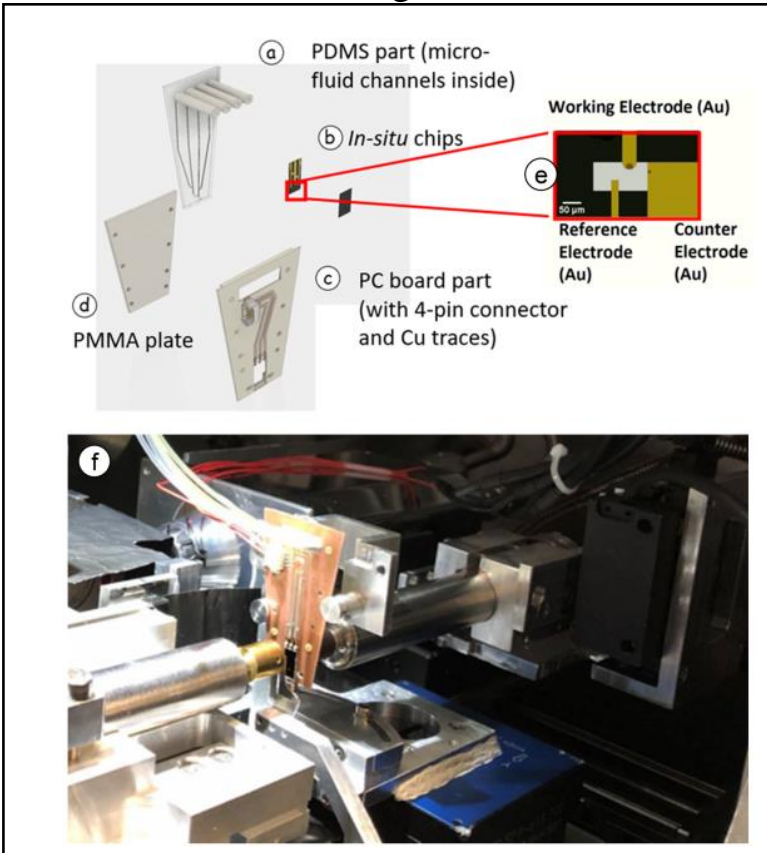

Figure 1. Microfluidic - based flow electrochemical cell for in situ and operando electrocatalysis studies [12]. (a-e) Details of the cell. The SiNx window area is $240 \mu \mathrm{m}$ wide and $100 \mu \mathrm{m}$ high. The active measurement area (dark circle on the WE) is $20 \mu \mathrm{m}$ diameter, and has a $\sim 10 \mathrm{~nm}$ Au thickness (plus $100 \mathrm{~nm} \mathrm{SiNx}$, and 2-3 $\mathrm{nm} \mathrm{Cr}$ ). (f) Photo of the cell inside the CLS ambient STXM.
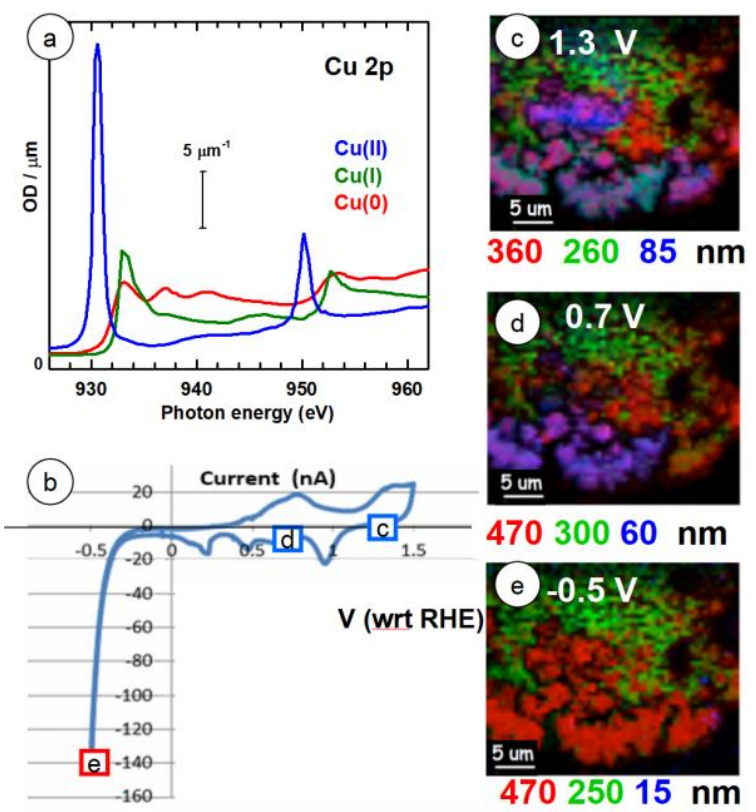

Figure 2. In-situ $\mathrm{CO}_{2}$ reduction on in situ electrodeposited $\mathrm{Cu}$. (a) Quantitative (OD1) $\mathrm{Cu} 2 \mathrm{p}$ reference $\mathrm{X}$ ray absorption spectra used to map oxidation states. (b) in-situ $\mathrm{CV}$ recorded after changing electrolyte from 5 $\mathrm{mM} \mathrm{CuSO}_{4} / 25 \mathrm{mM}\left(\mathrm{NH}_{4}\right)_{2} \mathrm{SO}_{4}$ to $0.1 \mathrm{M} \mathrm{NaHCO}_{3}$. (c e) $\mathrm{Cu}$ oxidation state maps at $1.3 \mathrm{~V}, 0.7 \mathrm{~V}$ and $-0.5 \mathrm{~V}$ w.r.t. RHE. The numbers below each map are maximum thickness in nm of $\mathbf{C u}(\mathbf{0}), \mathbf{C u}(\mathbf{1})$ and $\mathbf{C u}(\mathbf{2})$ derived from fitting a $\mathrm{Cu} 2 \mathrm{p}$ stack to the reference spectra in (a). 